\title{
PENGARUH GAYA KEPEMIMPINAN DAN KOMUNIKASI ORGANISASI TERHADAP KEPUASAAN KERJA PADA BP3IP JAKARTA
}

\author{
Atria Maharani ${ }^{*}$, Ratna Kurnia Dewi ${ }^{2}$ \\ 1,2Politeknik Bumi Akpelni, Jl. Pawiyatan Luhur II/17, Bendan Dhuwur, Semarang, \\ Indonesia \\ * Corresponding Author. E-mail : atria.maharani@akpelni.ac.id. Telp : +62 813-9171- \\ 9468
}

\begin{abstract}
Abstrak
Tujuan penelitian ini adalah untuk mengetahui seberapa besar pengaruh gaya kepemimpinan dan komunikasi organiasasi pada BP3IP Jakarta terhadap kepuasaan kinerja pegawainya. Metode pengumpulan data yang digunakan oleh peneliti adalah melalui data primer dan sekunder yang diperoleh melalui wawancara dan pengamatan (observasi) dilingkungan kantor BP3IP Jakarta. Dari hasil permbahasan diperoleh bahwa : 1) gaya kepemimpinan mempunyai dampak positif dan signifikan dengan kepuasan kerja instansi, 2) pelaksanaan komunikasi organisasi masih memerlukan perhatian yang lebih lanjut dari instansi, walaupun secara umum pelaksanaan komunikasi organisasi sudah berjalan dengan baik. Akan tetapi dengan melihat situasi, perlu perluasan kelas komunikasi organisasi, karena hal ini dapat memberikan kenyamanan dan kebebasan dalam mengembangkan kreatifitas pegawai, dan perubahan evaluasi karena adanya penilaian komunikasi organisasi yang professional.
\end{abstract}

Kata Kunci: Kepemimpinan, Komunikasi Organisasi, Kepuasaan Kerja

\begin{abstract}
The purpose of this study was to determine how much was the influence of the leadership style and organizational communication on BP3IP Jakarta toward its officers' performance satisfaction. The data collection method used by the researchers was through primary and secondary data obtained from interviews and observations in BP3IP Jakarta office environment. From the results of the discussion found that: 1) the leadership style had a positive and significant impact on the institution job satisfaction, 2) the implementation of organizational communication still required further attention from the institution, even though in general the implementation of organizational communication had gone well. However, by looking at the situation, it needed to broaden the organizational communication level, because this could provide comforts and freedoms in developing the officers' creativity, and evaluation because of the professional organization communication assessment.
\end{abstract}

Keywords: Leadership, Organizational Communication, Job Satisfaction 


\section{PENDAHULUAN}

BP3IP merupakan salah satu Unit Pelaksana Teknis (UPT) yang berada di lingkungan Kementerian Perhubungan bertugas untuk melaksanakan pendidikan kepelautan. Pembangunan disektor perhubungan dalam hal ini dimaknai sebagai upaya untuk meningkatkan kualitas sumber daya manusia yang dilakukan secara terus-menerus dengan memanfaatkan kemajuan ilmu pengetahuan dan teknologi, nasional dan global. Sebagai pengemban fungsi Pemerintah atau Badan Layanan Umum, Balai Pendidikan, Penyegaran, dan Peningkatan Ilmu Pelayaran Jakarta sesuai kapasitasnya, terus aktif melaksanakan pelayanan kepada masyarakat pelaut, khususnya dalam kegiatan penyediaan jasa pendidikan bagi tenaga kepelautan yang profesional.

Sumber daya manusia adalah aset kunci suatu instansi, mereka sebagai ujung tombak bisnis yang dapat memajukan atau merugikan instansi. Sumber daya manusia yang kompeten dengan kinerja yang baik dapat menunjang keberhasilan bisnis, sebaliknya sumber daya manusia yang tidak kompeten dan kinerjanya buruk merupakan masalah kompetitif yang dapat menempatkan instansi dalam kondisi yang merugi. Dengan semakin pentingnya peranan sumber daya manusia dalam suatu instansi, maka kinerja kerja pegawai harus ditingkatkan sementara itu dilain pihak tuntutan akan kepuasan pegawai juga semakin bertambah.

Meningkatkan kepuasan kerja pegawai sehingga kinerja pun dapat meningkat, tidak hanya dipengaruhi oleh faktor gaji semata. Akan tetapi ada beberapa faktor yang dapat meningkatkan kepuasan kerja pegawai dan kinerja pegawainya selain faktor tersebut, seperti gaya kepemimpinan dan komunikasi organisasi. Maka faktor gaya kepemimpinan, komunikasi antara pimpinan dengan bawahan dan pemberian imbalan/reward yang realistis serta prasarana kerja yang memadai diharapkan dapat mendukung kegiatan pelayanan terhadap taruna dan peserta diklat dalam proses pembelajaran oleh BP3IP Jakarta, agar penyusunan dan pelaksanaan kebijakan tersebut dapat terlaksana secara optimal.

\section{KAJIAN LITERATUR}

\section{Gaya Kepemimpinan}

Pendapat Soekarso, et al (2010:11), gaya kepemimpinan adalah perilaku atau tindakan pemimpin dalam mempengaruhi para anggota/pengikut serta melaksanakan tugas-tugas pekerjaan manejerial. Kemudian berdasarkan (Abdullah, 2010), gaya kepemimpinan merupakan norma perilaku yang digunakan oleh seseorang pada saat orang tersebut mencoba mempengaruhi perilaku orang lain seperti yang ia lihat. Mulyadi dan Veithzal Rivai (2009:72) menerangkan bahwa gaya kepemimpinan merupakan pola perilaku dan strategi yang disukai dan sering diterapkan oleh seorang pemimpin dalam rangka mencapai sasaran organisasi

Dalam teori kepemimpinan sedikitnya terdapat enam tipologi kepemimpinan yang dikenal dewasa ini, yaitu sebagai berikut (Soekarso, et.al, 2010:24-26):

a. Tipe Otoriter 
Adalah tipe pemimpin yang berbagai kegiatan yang akan dilakukan dan penetapan keputusan ditentukan sendiri oleh pemimpin semata-mata.

b. Tipe Demokratis

Adalah tipe pemimpin yang berbagai kegiatan yang akan dilakukan dan penetapan keputusan ditentukan bersama antara pemimpin dengan bawahan.

c. Tipe Liberal

Adalah tipe pemimpin yang berbagai kegiatan dan penetapan keputusan lebih banyak diserahkan pada bawahan.

d. Tipe Populis

Adalah tipe pemimpin yang mampu membangun rasa solidaritas pada bawahan atau pengikutnya.

e. Tipe Kharismatik

Adalah tipe pemimpin yang memiliki nilai ciri khas kepbribadian yang istimewa atau wibawa yang tinggi sehingga sangat dikagumi dan mempunyai pengaruh yang besar terhadap bawahan atau pengikutmya.

f. Tipe Kooperatif

Dimaksud sebagai kepemimpinan ciri khas Indonesia, yaitu kepemimpnan yang memiliki jiwa pancasila, yang memiliki wibawa dan daya untuk membawa serta dan memimpin masyawakat lingkungannya kedalam kesadaran kehidupan kemasyarakatan dan kenegaraan berdasarkan Pancasila dan UUD 1945.

Dalam teori kepemimpinan terdapat dua jenis gaya kepemimpinan yang utama, yaitu (Soekarso, et.al, 2010:44-45) :

a. Gaya berorientasi pada tugas (task oriented)

Adalah gaya kepemimpinan yang memusatkan perhatiannya pada tugas, yaitu penetapan dan menstruktur tugas. Dalam hal ini termasuk pembagian kerja, penjadwalan, sistem prosedur, petunjuk pelaksanaan, dan sebagainya yang kesemuanya mencakup penekanan aspek teknis atau penyelesaian tugas pekerjaan.

b. Gaya berorientasi pada orang (people oriented)

Adalah gaya kepemimpinan yang memusatkan perhatiaannya pada orang yaitu hubungan antar pribadi. Dalam hal ini mencakup saling percaya. Menghargai gagasan bawahan, membangun kerjasama, peka terhadap kebutuhan dan kesejahteraan bawahan.

\section{Komunikasi Organisasi}

Seperti Redding dan Sanborn mengatakan bahwa komunikasi organisasi adalah pengiriman dan penerimaan dalam organisasi yang kompleks. (dalam Muhammad 2009:65). Kemudian menurut Pace dan Faules dalam (Abdullah, 2010) mengklasifikasikan definisi komunikasi organisasi menjadi dua, yakni definisi fungsional dan definisi interpretative. Definisi fungsional komunikasi organisasi adalah sebagai pertunjukan dan penafsiran pesan diantara unit-unit komunikasi yang merupakan bagian dari suatu organisasi tertentu.

Menurut pendapat (Abdullah, 2010) ada lima penggolongan komunikasi dalam organisasi yang biasa dipakai, yaitu: 
a. Komunikasi Lisan dan Tertulis

Dasar penggolongan komunikasi lisan dan tertulis ini adalah bentuk pesan yang akan disampaikan. Banyak orang menyukai komunikasi lisan karena situasi keakraban yang ditimbulkannya, sedangkan orang lain berpendapat bahwa kecermatan dan ketepatan biasanya lebih berhasil dicapai melalui komunikasi lisan maupun tertulis, biasanya pada kesempatan atau saat yang berbeda dengan maksud untuk meningkatkan kemungkinan pemahaman atas pesan-pesan yang dikirimkan. Pada umumnya pesan-pesan lisan lebih mudah dan cepat dikirimkan, dan biasanya lebih murah dibandingkan pesanpesan yang disampaikan secara tertulis.

b. Komunikasi verbal dan non verbal

Menurut (Abdullah, 2010) jika dua orang berinteraksi, maka informasi mengenai perasaan dan gagasan-gagasan dan ide-ide yang timbul akan dikomunikasikan. Informasi mengenai perasaan seseorang dikemukakan secara lisan melalui apa yang dikatakan dan bagaimana mengatakannya. Arti dari kata atau kalimat diperjelas melalui tinggi rendahnya nada suara, perubahan nada suara, keras tidaknya suara, dan kapan komunikator berbicara. Perasaan seseorang juga dapat dinyatakan melalui berbagai isyaratisyarat atau signal-signal nonverbal dalam percakapan tatap muka langsung, perasaan, keadaan jiwa, atau suasana hati seseorang dinyatakan melalui gerakan isyarat (gesture), ekspresi wajah, posisi dan gerakan badan, postur, kontak fisik, kontak pandangan mata, dan stimulasi nonverbal lain yang sama pentingnya dengan kata-kata yang diucapkan.

c. Komunikasi ke bawah, ke atas, dan ke samping

Penggolongan komunikasi ke bawah, ke atas, dan ke samping (lateral) ini didasarkan pada arah aliran pesan-pesan dan informasi di dalam suatu organisasi. Untuk memperoleh pengertian yang lebih mendalam, maka berikut ini akan diuraikan ketiga jenis komunikasi tersebut sebagai barikut (Abdullah, 2010);

1) Komunikasi ke bawah

2) Komunikasi ke atas

3) Komunikasi ke samping

d. Komunikasi formal dan informal

Komunikasi dalam organisasi juga dapat digolongkan menjadi komunikasi formal dan komunikasi informal (Abdullah, 2010)

1) Komuniksi formal

Komunikasi formal terjadi di antara karyawan melalui garis kewenangan yang telah ditetapkan oleh manajemen. Komunikasi formal juga menetapkan saluran dimana komunikasi ke atas berlangsung, misalnya bawahan dapat didorong untuk menyatakan ide-ide, sikap, dan perasaan mereka sendiri, pekerjaan mereka, kebijaksanaan perusahaan, dan masalah-masalah sejenis yang melibatkan mereka.

2) Komunikasi informal

Komunikasi informal terjadi di antara karyawan dalam suatu organisasi yang dapat berinteraksi secara bebas satu sama lain terlepas dari kewenangan dan fungsi jabatan mereka. Biasanya komunikasi informal 
dilakukan melalui tatap muka langsung dan pembicaraan lewat telepon. Komunikasi informal terjadi sebagai perwujudan dari keinginan manusia untuk bergaul (sosialisasi) dan keinginan untuk menyampaikan informasi yang dipunyainya dan dianggap tidak dipunyai oleh rekan sekerjanya. Dengan mempelajari komunikasi informal dapat dilakukan penyesuaian-penyesuaian dalam organisasi formal guna mendukung komunikasi dan pencapaian tujuan organisasi. Fungsi utama dari komunikasi informal adalah memelihara hubungan sosial seperti persahabatan dan kelompok informal dan penyebaran informasi yang bersifat pribadi, gosip, dan desas- desus. Di samping itu, komunikasi informal dapat bersifat hubungan penugasan atau kedinasan (task related).

e. Komunikasi satu arah dan dua arah

\section{Kepuasan Kerja}

Kepuasan kerja adalah sikap umum terhadap pekerjaan seseorang, yang menunjukkan perbedaan antara jumlah penghargaan yang diterima pekerja dan jumlah yang mereka yakini seharusnya mereka terima (Robbins dalam Wibowo, 2007:299). Menurut Rivai dan Sagala (2009:856) kepuasan kerja merupakan evaluasi yang menggambarkan seseorang atas perasaan sikapnya senang atau tidak senang, puas atau tidak puas dalam bekerja. Kemudian menurut Luthans (2006:243) kepuasan kerja adalah hasil dari persepsi karyawan mengenai seberapa baik pekerjaan mereka memberikan hal yang dinilai penting.

Sedangkan menurut Rivai dan Sagala (2009:p856-857) teori tentang kepuasan kerja yang cukup dikenal ada 3 teori yaitu :

a. Teori ketidaksesuaian (Discrepancy theory)

Teori ini mengukur kepuasan kerja seseorang dengan menghitung selisih antara sesuatu yang seharusnya dengan kenyataan yang dirasakan. Sehingga apabila kepuasannya diperoleh melebihi dari yang diinginkan, maka orang akan menjadi lebih puas lagi, sehingga terdapat discrepancy, tetapi merupakan discrepancy yang positif. Kepuasan kerja seseorang tergantung pada selisih antara sesuatu yang dianggap akan didapatkan dengan apan yang dicapai.

b. Teori keadilan (Equity theory)

Teori ini mengemukakan bahwa orang akan merasa puas atau tidak puas, tergantung pada ada atau tidaknya keadilan (equity) dalam suatu situasi, khususnya situasi kerja.

c. Teori dua faktor (two factor theory)

Menurut teori ini kepuasan kerja dan ketidakpuasan kerja itu merupakan hal yang berbeda. Kepuasan dan ketidakpuasan terhadap perkerjaan itu bukan suatu variabel yang kontinu.

\section{METODE PENELITIAN}

Dalam penelitian ini digunakan metode survey dengan pendekatan korelasional. Alat ukur (instrumen) yang digunakan dari semua variabel yang diteliti baik kualitas, pengembangan pegawai, maupun kepuasan kerja adalah 
angket yaitu berupa daftar pernyataan yang diberikan kepada responden sesuai dengan sampel yang telah ditentukan. Penulis memilih penelitian survey dengan pendekatan deskriptif dengan alasan metode penelitian tersebut dapat menjelaskan pengaruh antara variable yang diteliti (Astriawati \& Setiyantara, 2019). Dalam hal ini variabel bebas terdiri atas gaya kepemimpinan (X1) dan komunikasi organisasi (X2), sedangkan variabel terikatnya adalah kepuasan kerja pegawai (Y).

Populasi dari penelitian ini adalah Pegawai Negeri Sipil tetap dan bukan honerer pada Balai Besar Pendidikan Penyegaran Dan Peningkatan Ilmu Pelayaran (BP3IP) Jakarta berjumlah 108 orang.

Sampel diambil dengan menggunakan rumus slovin sebagai berikut (Husein Umar, 2013:78)

$$
\begin{aligned}
& n=\frac{N}{1+N(e)^{2}} \\
\text { Dimana: } & \mathrm{n}=\text { Jumlah sampel yang diambil } \\
\mathrm{N}=\text { Populasi sampel } & \mathrm{e}=\text { Error margin }(1 \%, 5 \%, 10 \%) \text { digunakan } 10 \% \\
& \text { Maka diperoleh jumlah sampel penelitian sebagai berikut: } \\
n= & \frac{N}{1+N(e)^{2}}=\frac{108}{1+108(0,10)^{2}}=\frac{108}{1+1,108}=\frac{108}{2,08}=51,92308 \approx 52
\end{aligned}
$$

Dari hasil perhitungan di atas diketahui jumlah sampel penelitian sebanyak 52 orang responden.

\section{PEMBAHASAN}

\section{Bagaimana Pengaruh Gaya Kepemimpinan terhadap Kepuasaan Kerja Pegawai}

Gaya kepemimpinan dipandang mampu untuk meningkatkan peran serta dan sumbangan para anggota atau pegawai terhadap organisasi. Penelitian menunjukkan bahwa gaya kepemimpinan mempunyai dampak positif dan signifikan dengan kepuasan kerja instansi. Kualitas kehidupan kerja dapat ditingkatkan melalui pertumbuhan dan pengembangan, partisipasi, upah dan keuntungan serta lingkungan kerja. Hal ini berarti bahwa upah dan keuntungan serta lingkungan kerja sangat mempengaruhi gaya kepemimpinan pegawai. Sehingga jika manajemen ingin meningkatkan kepuasan kerja melalui gaya kepemimpinan pegawai maka hal yang harus diperhatikan adalah sistem dan struktur pemberian kompensasi langsung dan tidak langsung (pemberian upah dasar dan berbagai keuntungan/manfaat) yang kompetitif dan dapat mensejahterakan pegawai serta dengan menyediakan lingkungan kerja yang mendukung terciptanya suasana kerja yang harmonis dan dinamis sehingga diharapkan dapat meningkatkan komitmen organisasin dan kepuasan kerja pegawai. 


\section{Bagaimana pengaruh Komunikasi Organisasi terhadap Kepuasaan Kerja Pegawai}

Pelaksanaan komunikasi organisasi masih memerlukan perhatian yang lebih lanjut dari instansi, walaupun secara umum pelaksanaan komunikasi organisasi sudah berjalan dengan baik. Akan tetapi dengan melihat situasi perlu peluasan kelas komunikasi organisasi, karena hal ini dapat memberikan kenyamanan dan bias mengembangkan kreatifitas pegawai, dan perubahan evaluasi karena dengan penilaian komunikasi organisasi yang professional, pegawai akan mengurangi kecemburuan dan iri hati terhadap teman kerjanya dan pegawai akan termotivasi untuk meningkatkan keterampilan dengan demikian sebaiknya instansi lebih memperhatikan pelaksanaan komunikasi organisasi pegawai, karena dengan memiliki pegawai yang berkompeten maka masa depan instansi akan lebih baik lagi. Berdasarkan hasil penelitian mengenai kepuasan kerja pegawai, instansi harus lebih meningkatkan lagi komunikasi pegawai dengan pihak instansi, agar apa yang menjadi tujuan instansi dapat tercapai.

\section{PENUTUP}

\section{Kesimpulan}

Gaya Kepemimpinan mempunyai pengaruh yang signifikan terhadap kepuasaan kerja pegawai karena dengan kepemimpinan yang sesuai kinerja pegawai akan meningkat serta tujuan organisasi terpenuhi. Komunikasi organisasi berpengaruh terhadap kepuasaan kerja pegawai. Dibutuhkan komunikasi organasasi guna menunjang hubungan baik komunikasi pegawai secara vertikal maupun horizontal antara bawahan dengan atasan maupun sesama teman diantara unit kerja.

\section{DAFTAR PUSTAKA}

Abdullah, M. (2010). Komunikasi Organisasi Dalam Perspektif Teori dan Praktek. Malang: UPT Penerbitan Universitas Muhammadiyah Malang.

Astriawati, N., \& Setiyantara, Y. (2019). Pengaruh Pendekatan Realistic

Mathematics Education Bidang Teknika Pelayaran Dalam Meningkatkan Minat Belajar Taruna. Majalah Ilmiah Bahari Jogja. https://doi.org/10.33489/mibj.v17i1.186

Malayu S. P. Hasibuan (2008) Manajemen : Dasar, Pengertian dan Masalah Kepemimpinan, Bumi Aksara Jakarta

Mangkuprawira (2007) Manajemen Mutu Sumber Daya. Manusia. Ghalia Indonesia, Bogor.

Masmuh, Abdullah. (2010). Komunikasi Organisasi dalam Perspektif Teori dan Praktek. UMM Press, Malang

Mathis, Robert L. \& John H. Jackson. (2006). Human Resource Management: Manajemen Sumber Daya Manusia Edisi ke-10. Edisi Bahasa Indonesia. Salemba Empat, Jakarta.

Nur Indriantoro dan Bambang Supomo (2006) Metodologi Penelitian Bisnis,. Cetakan Kedua, Yogyakara; Penerbit BPEE UGM. 
Oei, Istijanto. (2010). Riset Sumber Daya Manusia. PT Gramedia Pustaka Utama, Jakarta

Pace, Wayne dan Faules, Don F. (2006). Komunikasi Organisasi. PT Remaja Rosdakarya, Bandung

Priyatno, Duwi (2012) Mandiri Belajar SPSS, Cetakan Ketiga, Yogyakarta: Media Kom 